\title{
Improving Accuracy of Manual Crimping Operation through the Automation of Crimping Machine
}

\author{
Vishal M. Dhumal, Shivam R. Kanade, Samadhan U. Bandagar, Kiran S. Ghule, \\ Kiran V. Chandan, Manoj R. Shewale
}

\begin{abstract}
Crimping machine is used in wire harnessing operation for creating a joint between wire and crimping pin with pressing of conductor crimp and insulation crimp. The holding of wire is done by manually without any guiding to the worker . So accuracy of crimping machine is mainly depending upon the skill of worker to hold the wire at accurate position. So for accurate joint, worker plays an important role. Guiding to worker is important so that accuracy will not depend upon worker efficiency and skill. So to achieve the right position to launch pressing die to go for pressing sensor should be at right position. For sensing the accurate position the sensor model which constitute Arduino, color recognition sensor, etc, which help to sense the change in color on insulation of wire. This color change is done by using the marker and sensed in the form of frequency change as marking of different color is done on the wire. This helps Arduino to work as mentioned in program to identify change in color frequency. Then through the LED attached on Arduino signal come to worker as the wire is at accurate position. Then pedal is activated by Arduino to do pressing operation. This will reduce the work done by worker and provide guidance to worker for working in any condition or situation.
\end{abstract}

Index Terms: Arduino, Crimping machine, sensor, wire harness.

\section{INTRODUCTION}

Now days, the companies are facing the problems regarding the worker efficiency, skills, accuracy of certain operation, etc. in manufacturing. These companies are looking for automation as a solution of this problem. So achieving the automation in company Core-Tech Aurangabad Pvt. Ltd. has facing the problem of lack in accuracy due to many problems in crimping machine [1]. Normally they do 1200 to 1500 crimping operation in a day. In that 40 to 50 fails due to the improper attachment of crimping with wire. This problem occur due to the many reasons some of them are not holding

wire at accurate position between crimping pin and punch [2], proper load applied on the crimping pin joint, etc. Crimping pin with conductor crimp and insulation crimp is shown in fig

Vishal M. Dhumal, UG Student, Mechanical Department, SVERI's College of Engineering, Pandharpur, Maharashtra, India.

Shivam R. Kanade, UG Student, Mechanical Department, SVERI's College of Engineering, Pandharpur, Maharashtra, India.

Samadhan U. Bandagar UG Student, Mechanical Department, SVERI's College of Engineering, Pandharpur, Maharashtra, India.

Kiran S. Ghule, UG Student, Mechanical Department, SVERI's College of Engineering, Pandharpur, Maharashtra, India.

Kiran V. Chandan, Assistant Professor, Mechanical Department, SVERI's College of Engineering, Pandharpur, Maharashtra, India.

Manoj R. Shewale, Director, Coretech Aurangabad Pvt. Ltd. Waluj MIDC, Aurangabad, Maharashtra, India.
1. The crimping machine before experimentation is shown in fig.2. The normal joint formed between crimping pin and wire is given in fig.3.

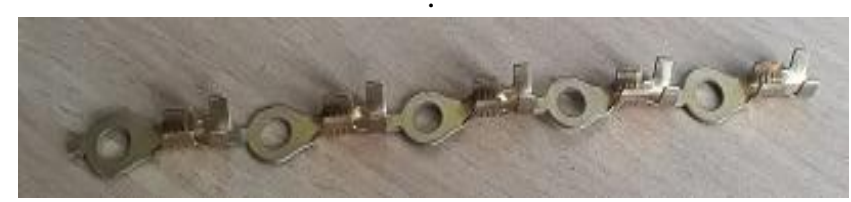

Fig.1 Crimping pin

Project objectives are as follows

1) To guide the worker about the accurate position between the crimping pins and punch

2) To increase the productivity by reducing the losses due to worker inefficiency

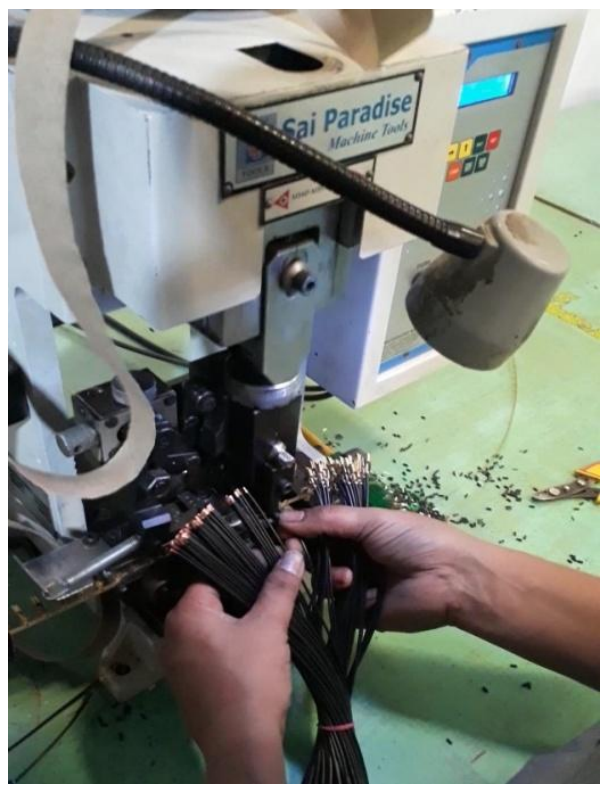

Fig.2 Crimping Machine

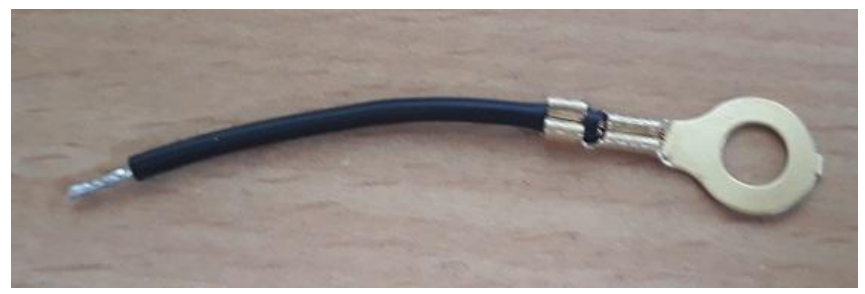

Fig.3 Crimping Operation.

\section{LITERATURE REVIEW}

Klaus states about the stroke of crimping machine and the necessity of managing the stroke length for accurate 
crimping joint between electric conductor and electric connector.[1]

Gerst explains about the automatic crimping tool and crimping is done on the basis of carrier steep mechanism. [2] Basic information of Arduino and its pin is useful for doing experimentation on it. The utilization of Arduino software in giving the program to Arduino is done by Arduino IDE. [3]

The sorting of object is a very difficult to maintain his proper place. Because in industry the continuous process of operations is done. Sensor Color Reorganization- tcs3200 will help to maintain the sorting of the products. [4]

Wiring harness is a predetermined structural set of wire, terminal and connecter thought vehicle body for providing electrical supply. It is used for connecting the electrical devices for automotive vehicle .The wire harness thus connected to electric devices by engaging each set of harness end terminals with each electric device connector attached to the vehicle frame. [5]

\section{COMPONENTS OF SENSOR MODEL}

\section{A. Arduino Uno}

The Arduino Uno is used for programming purpose especially for color recognition sensor. The Arduino has two microcontrollers, one reset button, one USB connection port, adapter port, 13 input output pins, etc. The first microcontroller is used for making interface between the second microcontrollers to load program, change program, etc [1]. The second microcontroller is used for actual performance as the program is loaded on that. The reset button is used for clearing second microcontroller program loaded on it. The 13 pin is specially provided with LED for indication of result. The many pins ground pin, input/output pins having voltage are present.

\section{B. Color Recognition Sensor TCS 3200}

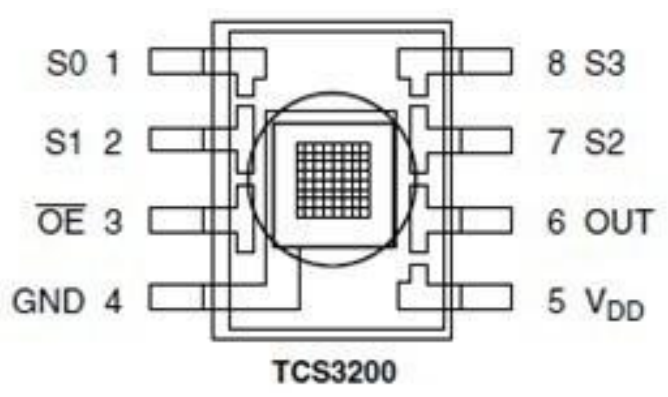

Fig. 4 Color Reorganization Sensor [4].

This sensor has 8 pins which controls the input and output of a sensor. On that $\mathrm{S} 0$ and $\mathrm{S} 1$ are recognized as output frequency control ports and S2 and S3 are used color light to detect. There are also ports like GND, VCC, OUT and OE. These ports have special meaning like having the ground the voltage as shown in fig. 4 .

\section{Cables}

As different types of jumper cables are used like male to male, female to female, male to male jumper cables which is are used to make the connection between the Arduino and sensor. USB cable is also used for making interface between the Arduino and computer.

\section{Relay}

Relay is an electromagnetic switch used for turn on and off circuit. The main parts of relay are electromagnet, movable arm, switch point contacts. The relay has mainly two circuits control circuit and load circuit.

\section{ASSEMBLY OF COMPONENT}

The assembly is done in Arduino and sensor by following ways in Fig.5.

The S0 pin is attached with the 4 number port and S1 port is attached with 5 number ports on 13 input output pins on Arduino board [1]. The S2 and S3 normally known as a current to frequency converter ports which are used for output port are attached to 6 and 7 number of ports. Ground port is attached to GND port of Arduino to ground the supply. OUT port is attached with the 8 number of port on the Arduino board [4]. This all connection is done through the male to female jumper cables. Then Arduino is joined with the USB cable to the pc. Then reset button is pressed on Arduino for clearing the past program from Arduino board. Then through the ArduinoIDE new program can be loaded. [1]

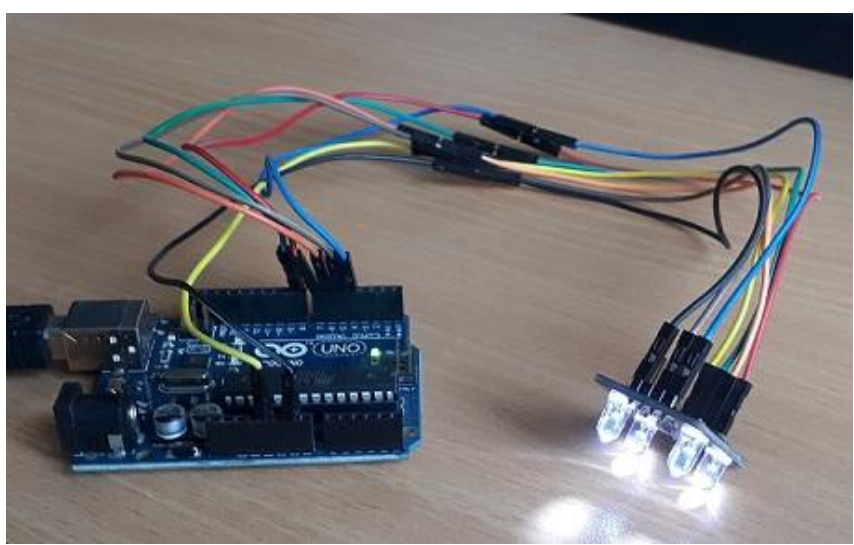

Fig.5 Assembly of Components

\section{WORKING OF COMPONENTS}

The checking of components is done by analyzing the various parameters like sensor output result and input result. The various constraints are applied for the sensor through the program. In program if S0 and S1 are provided with low and high value then the change in this values gives frequency scaling as per needed. As low and low to S0 and S1gives the result as power down. This is shown as in Table 1.

Table 1: Output Response for S0 and S1

\begin{tabular}{|l|l|l|}
\hline S0 & S1 & Output Response \\
\hline LOW & LOW & No Response \\
\hline LOW & HIGH & High scaling \\
\hline HIGH & LOW & Medium scaling \\
\hline HIGH & HIGH & Low scaling \\
\hline
\end{tabular}

As the sensing the small color change the high scaling of output is used. For that purpose S0 is provided with low and $\mathrm{S} 1$ is provided with high. This helps to achieve response in RGB color frequencies on pc. For the S2 and S3 port for 
focusing on the specific color the one from RGB color is chosen for that Table 2 is provided.

Table 2: Output color frequency for S2 and S3

\begin{tabular}{|l|l|l|}
\hline S2 & S3 & Color Frequency \\
\hline Low & Low & Red \\
\hline Low & High & Blue \\
\hline High & Low & No color \\
\hline High & High & Green \\
\hline
\end{tabular}

As specifically the wire has much color in that red is chosen for the experiment purpose. So that $\mathrm{S} 2$ is provided with low and S3 is also provided with low. By looking at the $\mathrm{pc}$ we can find different values of red color coming from the diodes. This color frequency readings coming from Arduino are used for sensing the change in color of the wire.

\section{EXPERIMENTATION}

\section{A. Program for Arduino}

The program for Arduino is done on the Arduino IDE software in normal coding technique. The normal program for color recognition is used for the sensor and some changes in the program are done like using if statement for specific frequency selection, using of only red color than green, blue so that specific color frequency will appear. Use of if statement as if normal color of wire is blue then the frequency on monitor will come about 1100 to 1110 but if the color changed then frequency will reduce or increase as per the marking color used. Normally black color is used so that increase in the frequency is used. IF (frequency>1115) then show the LED light and activate the relay circuit. Then the relay is activated as the correct position is achieved. The pressing operation is done by punch. For black color of wire white color is used which decrease the frequency so that ' $<$ ' symbol is used.

\section{B. Performance.}

To hold the sensor at the accurate position the holding stand is used. This will help to block the sunlight coming from outside to the sensor and also provide support to it. The material used for the stand is nylon and square shape nylon three plates of side $4 \mathrm{~cm}$ are taken and then one plate is cut with center dimensions of sensor as shown in Fig.6. Then the sensor is hold closed to crimping line at a distance of $2 \mathrm{~cm} \mathrm{[3].}$ Then consider the different wires of length and marking is done on $4 \mathrm{~cm}$ length. The marking length is of $2 \mathrm{~mm}$ to $4 \mathrm{~mm}$ are made.

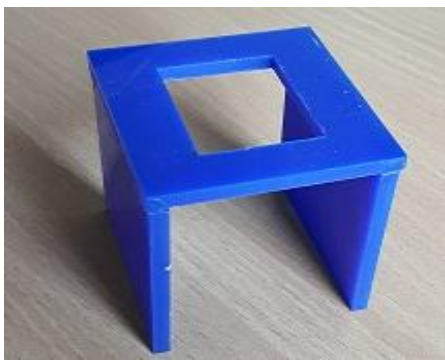

Fig.6 Holding Stand for sensor

These dimensions are specified due to obtain change in color frequency. The Arduino takes reading in mille seconds for each time. So the time required for reading and checking is less than one second. If the wire is at accurate position then the LED get activated and the control circuit of relay is get completed and this will complete the circuit of between the pressure pedal and relay so that punch will activated for pressing operation as shown in fig.7.

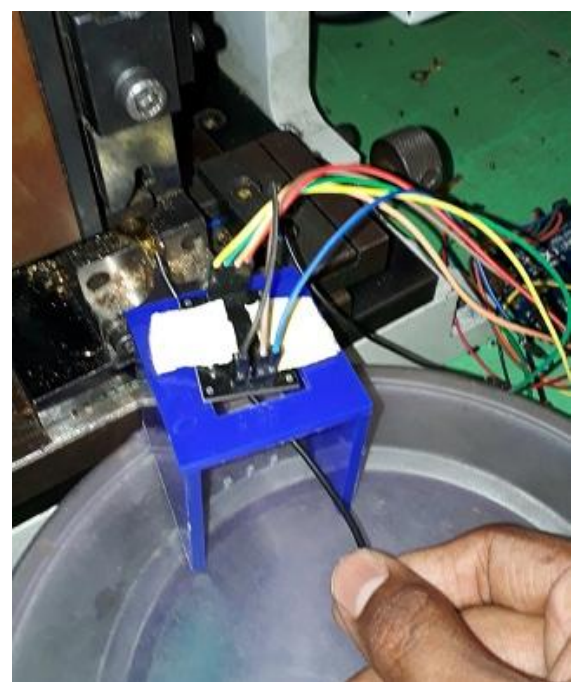

Fig.7 Actual Performance of Model

\section{RESULT}

The sensor module work properly giving following results-

1. Guides worker for good crimping operation.

2. Give good efficient crimping joint between wire and crimping pin.

3. Accuracy and precision of crimping operation is maintained.

4. Productivity of operation is maintained as operation takes less time.

5. The rejection rate of crimping operation is less as between 2 to 10 for a day.

\section{CONCLUSION}

Experimentation performed in the paper is satisfying the company as worker efficiency and skills are not playing any vital role in achieving the accuracy of crimping operation. The time required for the operation is 1 to $2 \mathrm{sec}$. The productivity is increased as the accuracy is increased and time required is less. The marking on the wire should be accurate to achieve best results.

\section{ACKNOWLEDGMENT}

The author wish to thanks the director Mr. Manoj Shewale Coretech Pvt. Ltd. Aurangabad, Dr. B. P. Ronge, Principal of College of Engineering Pandharpur \& Guide Mr. K.V. Chandan.

\section{REFERENCES}

[1]. Enneper, K., Monsieur, D. and Schwager, E., Kabelwerke Reinshagen GmbH, 1992. Crimping machine. U.S. Patent 5,168,736.

[2]. Gerst, M., Sasse, T. and Zajicek, J., Whitaker Corp, 1998. Automatic crimping tool. U.S. Patent 5,752,405

[3]. Arduino, S.A., 2015. Arduino. Arduino LLC.

[4]. Soetedjo, A., Ashari, M.I. and Ardiles, C., 2017. Development of Industrial Control Training Module using Distance and Color Sensors 
for Detecting Objects. International Journal of Engineering and Management, 1(1), pp.1-8.

[5]. Adachi, M., Sumitomo Wiring Systems Ltd, 2003. Structure for wiring a wire harness between an automobile body and a mobile article, and a method of protecting an electric wire group of a wire harness. U.S. Patent 6,635,825. 